\section{Effect of Didecyldimethylammonium Bromide against Powdery Mildews and other Fungal Plant Diseases}

Catronic surface-active agents are widely used as bactericides, and in recent years have been applied against a number of fungi of medical importance ${ }^{1}$. Certain agents of this type have been included in investigations at this Station of chemicals of potential value for the control of fruit diseases, especially apple mildew, Podosphaera leucotricha (Ell. and Ev.) Salm. Among these, didecyldimethylammonium bromide (DDAB) was outstanding both for wetting of foliage and for disease control. In all experiments, it was used as the commercial 50 per cent liquid preparation that is already widely used in the food and beverage industries, but concentrations quoted here are in terms of active ingredient for all materials.

Using a settling-tower procedure for inoculation of apple rootstocks with powdery mildew ${ }^{2}$, we have found that protection of young foliage against this disease is elated to the wetting power of the cation ic surface-active agent used. Thus the well-known agent, cetrimide (cetyl tetradecyl trimethylammonium bromide), at 0.025 per cent, wets apple rootstock foliage only moderately and gives little protection against mildew. DDAB, at the same concentration, sets such foliage extremely well and providos a high level of protection against this disoase.

In a comparison of DDAB with the phenolic material DNOP, obtained by hydrolysis of crude dinocap extracted from the American commercial wettable powder, DDAB was intrinsically inferior as a protective agent. However, the curative (post-infection) control given by 0.025 per rent DDAB applied 5 days after inoculation was virtually complete.

Experiments late in the season with heavily infected motstocks have shown that one application at 0.05 per cent was sufficient to eliminate visible signs of sporulating roycelium for more than two weeks.

In the field a programme of DDAB at 0.05 per cent applied at intervals of 10-14 days until the ond of June to Cox's Orange Pippin trees gave significantly $(P<0.01)$ better control of apple mildew, as judged by secondary infections recorded in August, than one of captan plus dinocap, but produced more russet-blemish on some of the fruits.

With the settling-tower technique on potted seedlings of barley, var. Plumage Archer ${ }^{2}$, more than 90 per cent control of mildew, Erysiphe graminis DC, was given without damage by protective applications of DDAB at 0.05 per cent, dinocap at 0.005 per cent, and the organophosphorus fungicide, 'W.P. 155', at 0.02 per cent.

In glasshouse tests, DDAB gave superior control of strawberry mildew, Sphaerotheca macularis (Wallr. ex Fries) Jaczewski, to that given by DNOP, dinocap, cetrimide, lime-sulphur, or actidione oxime. But in a late-season, small-scale field trial on the variety Cambridge Rearguard, lime-sulphur and dinocap gave more lasting control.

As sprays for control of apple mildew are usually combined with those for control of apple scab, experiments were also begun with DDAB for control of this disease. In a glass-slide tost with conidia of $V$. inaequalis (Cke.) Wint., germination was inhibited almost to the same extent as by captan at the same concentrations. In a test of curative action in the glasshouse on potted MM. 109 apple rootstocks sprayed with various concentrations of DDAB $24 \mathrm{~h}$ after an optimal period for infection had been given, control at 0.05 per cent was fully comparable with that to be expected from 0.0015 per cent mercury as phenylmercuric chloride (PMC).

Of the compounds examined by a glasshouse technique developed for examining the action of fungicides on sporulating lesions of Gloeosporium perennans Zeller and Childs, DDAB has shown great promise, and at 0.05 per cent was almost equal to $0 \cdot 1$ per cent $\mathrm{PMC}$ in suppressing spore production. The field trial on apples already mentioned is designed to give evidence of field performance against mildew, scab and Gloeosporium.

There was no indication that DDAB damaged apple foliage in the field, and in glasshouse tests on rootstocks concentrations up to $\mathbf{0 . 2}$ per cent were safe; the problem raised by the russeting of apple fruits will be examined further, in view of the apparent promise of DDAB (and perhaps of related compounds) as a field fungicide.

\section{A. H. M. K'RBY \\ E. L. Frick}

Plant Protective Chemistry Section,

R. T. BURCHILI

M. H. MOORE

Plant Pathology Section,

East Malling Research Station, Nr. Maidstone, Kent. ${ }^{1}$ Taylor, E. P., and D'Arcy, P. F., in Progress in Medicinal Chemistry, 1961).

${ }^{2}$ Kirby, A. H. M., and Frick, E. L., Ann. Appl. Biol. (in the press).

\section{A Nematotoxin produced by the Nema- tophagous Fungus Arthrobotrys oligospora Fresenius}

The nematopagous fungus, Arthrobotrys oligospora Fres., captures nematodes by means of adhesive hyphal networks. When a nematode has been snared, the fungus pierces the animal's integument and produces a bulbous structure from which trophic hyphæ grow throughout the body of the worm. Drechsler ${ }^{1}$ attributes the death of the nematode to the partial severance of its body by the infection bulb of the fungus. This view is not shared by Shepherd ${ }^{2}$, who found that the captured nomatode becomes inactive before tho infection bulb has completely developed. Duddington ${ }^{3}$ supports Shepherd's view and suggests that a toxin, capable of paralysing or killing, may be secreted by the adhesive trapping organs and act externally, or that such a substance may be transported internally by way of the fine penetration peg through the nematode cuticle. Soprunov and Galiulina ${ }^{4}$ claim to have detected a secretion by a hyphal network-forming species which paralyses nematodes.

In view of the conflicting reports and opinions regarding the actual cause of death of the captured nematode, it was decided to investigate this aspect of the nematode host fungus parasite relationship.

The fungus, $A$. oligospora, was cultured in a 0.3 per cent yeast-extract amended Czapek's broth at $26^{\circ} \mathrm{C}$. Seitz filtered, sterile extracts of this fungus had no apparent effect on the vitality of nematodes of Rhabditis sp. when they were immersed in the filtrate for periods up to $24 \mathrm{~h}$. Sterile filtrates from crushed nematodes also had no adverse effect on living nematodes which were immersed in various concentrations of them for similar periods. But, when living nematodes were placed in a filtrate obtained from crushed nematodes which had been parasitized by the fungus, many of them became inactive and appeared to have been killed by some substance in the filtrate. After transferring the inactivated nematodes to tap-water a number of them revived.

In repetitions of the experiment it was found that about 30 per cent of tho nematodes became inactive during a 2 -h period of immersion in filtrates from fungusparasitized nematodes and that practically all of these revived when placed in tap-water. If the nematodes wero in the filtrate for $12.24 \mathrm{~h}$, approximately half of them became inactive, and about 30 per cent of these were found to have died. 'They did not revive when placed in tap-water.

Since the osmotic pressure of the lethal filtrate was far below levels known adversely to affoct nomatodes ${ }^{6}$, it is 